\title{
Drastically Increase in Atomic Nitrogen Production Depending on the Dielectric Constant of Beads Filled in the Discharge Space
}

Yuto Tsuchida, ${ }^{\dagger}$ Naoya Murakami, ${ }^{\dagger \dagger}$ Tatsuya Sakakura, ${ }^{\dagger}$ Yoshiyuki Takatsuji, ${ }^{\dagger}$ and Tetsuya Haruyama ${ }^{\dagger *}$

${ }^{\dagger}$ Division of Functional Interface Engineering, Department of Biological Functions and Engineering, Kyushu Institute of Technology, Kitakyushu Science and Research Park, Fukuoka 808-0196, Japan

${ }^{\# D}$ Division of Photo-functional Nanomaterials, Department of Biological Functions and Engineering, Kyushu Institute of Technology, Kitakyushu Science and Research Park, Fukuoka 808-0196, Japan

*Corresponding author Email: haruyama@life.kyutech.ac.jp

$\mathrm{NH}_{4}^{+}$

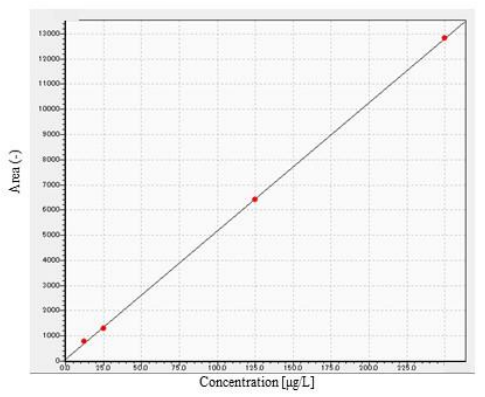

$\mathrm{NO}_{3}-$

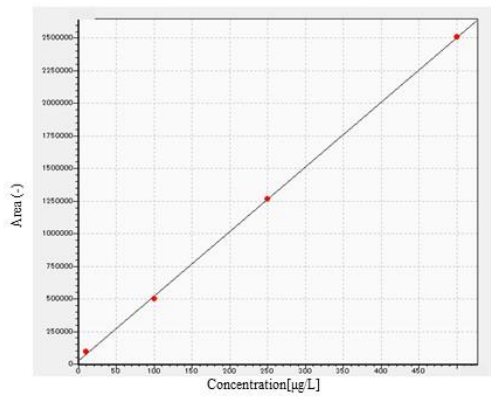

$\mathrm{NO}_{2}^{-}$

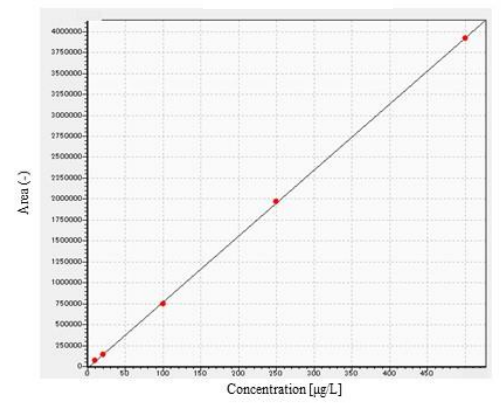

Figure S1 Standard sample, calibration curve, and calibration curve accuracy for analyzing ammonium ions, nitrate ions, and nitrite ions by ion chromatography. Correlation coefficient $(\mathrm{R})$ : Ammonium ion $\left(\mathrm{NH}_{4}{ }^{+}\right) \mathrm{R}=0.9999$, Nitrate ion $\left(\mathrm{NO}_{3}{ }^{-}\right) \mathrm{R}=0.9998$, Nitrite ion $\left(\mathrm{NO}_{2}{ }^{-}\right) \mathrm{R}=0.9999$.

\section{Standard chemicals:}

All standard chemicals were purchased from Wako Chemicals Co., Ltd. Ammonium ion $\left(\mathrm{NH}_{4}{ }^{+}\right)$: Ammonium ion standard solution $\left(\mathrm{NH}_{4} \mathrm{NO}_{3}\right.$ aq.)

Nitrate ion $\left(\mathrm{NO}_{3}{ }^{-}\right)$: Nitrate ion standard solution $\left(\mathrm{NaNO}_{2}\right.$ aq.)

Nitrite ion $\left(\mathrm{NO}_{2}^{-}\right)$: Nitrate ion standard solution $\left(\mathrm{NaNO}_{3}\right.$ aq.)

\section{Analysis conditions}

Cation chromatography

Elution phase: $3.0 \mathrm{mM}$ Methanesulfonic acid aq.

Flow rate: $1.9 \mathrm{~mL} / \mathrm{min}$

Column temperature: $40^{\circ} \mathrm{C}$

Anion chromatography

Elution phase: $3.6 \mathrm{mM}$ Sodium carbonate aq.

Flow rate: $0.8 \mathrm{~mL} / \mathrm{min}$

Column temperature: $45^{\circ} \mathrm{C}$ 

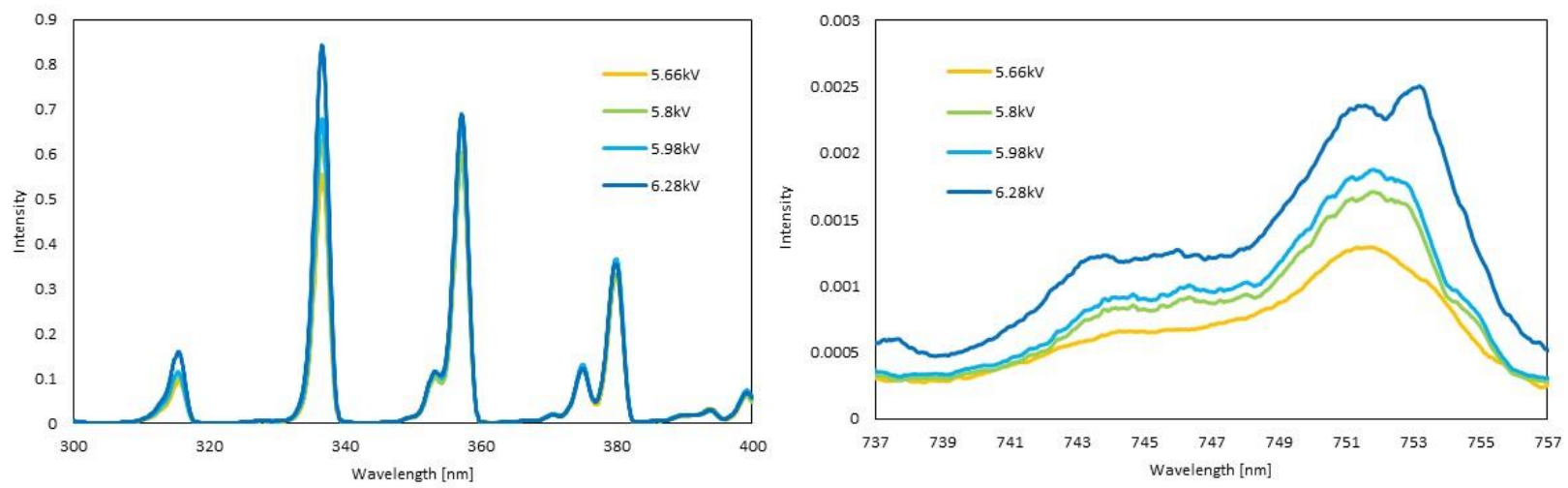

Figure $\mathbf{S 2}$ Discharge voltage dependence of plasma emission spectra of $\mathrm{N}_{2}{ }^{+}$and $\mathrm{N}_{2}{ }^{*}$ (left), and $\mathrm{N}_{\text {atom }}$ (right). 

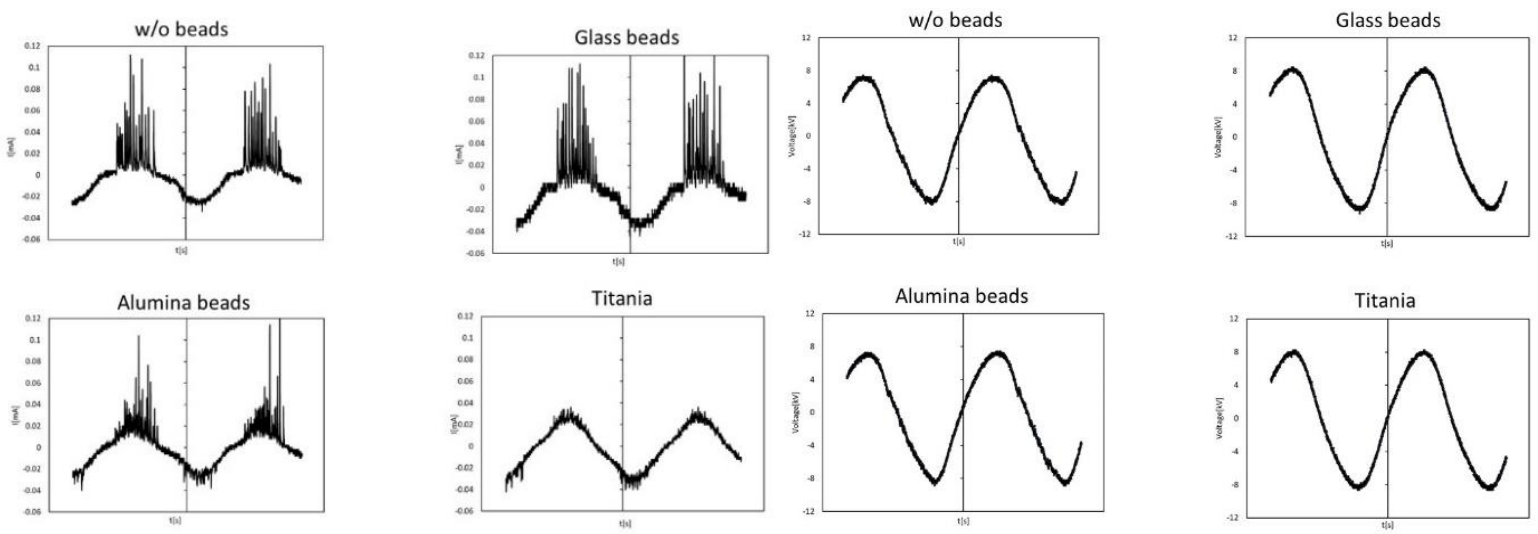

Figure S3 (a) Oscillograms of discharge conducted under four different conditions: filled with glass, alumina, or titania beads, and without the use of dielectric beads.
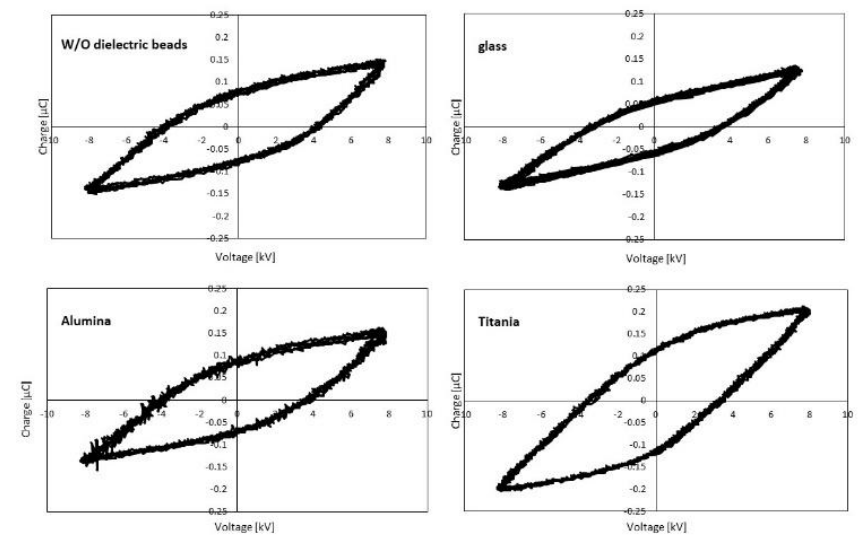

Figure S3 (b) Lissajous plots of discharge conducted under four different conditions: filled with glass, alumina, or titania beads, and without the use of dielectric beads. 


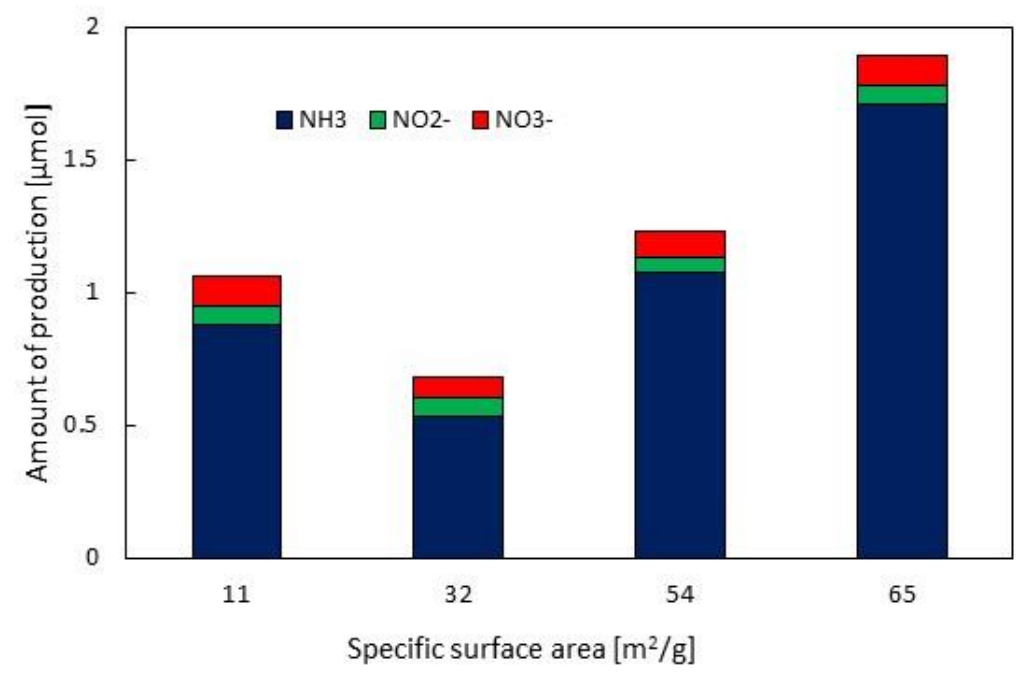

Figure S4 Amount of each product in the phase interface reaction performed by means of packed-bed dielectric barrier discharge when filled with four types of titania beads (same macro diameter) with different specific surface areas.

Due to the difference in specific surface area caused by the pores of titania, a change was observed in the total production amount as shown in the histograms above. Differences in specific surface area can have some effect on the discharge. However, when titania is used as the dielectric beads to be filled in the discharger, the $\mathrm{P} / \mathrm{L}$ reaction still has high ammonia production selectivity. 


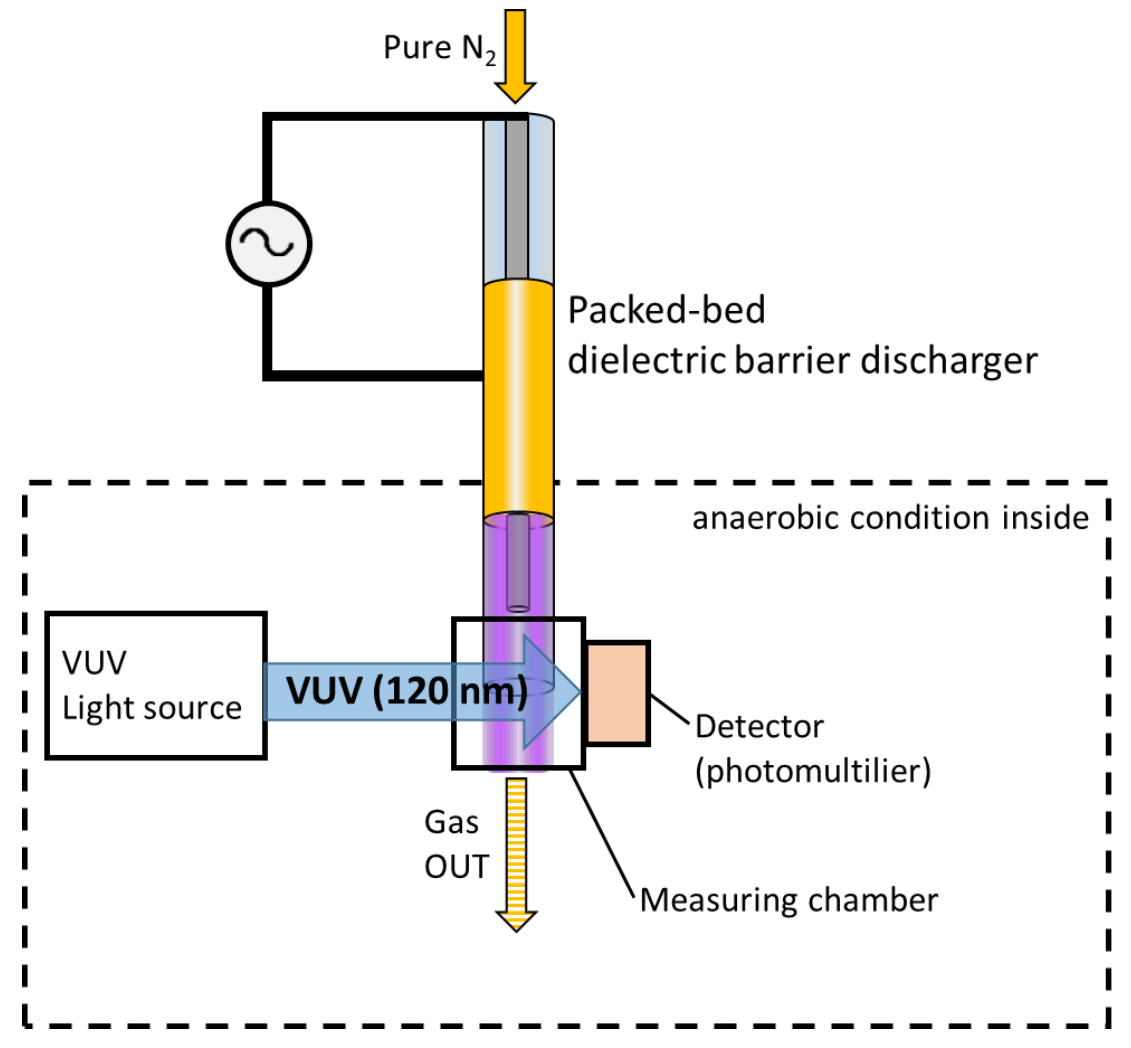

Figure S5 VUV spectroscopic system for quantification of atomic nitrogen

Monochromatic light of $120 \mathrm{~nm}$ was extracted from a deuterium lamp using a monochromator. An optical chamber was mounted at the output of the monochromator through the magnesium fluoride window. The output gas of the discharger was introduced into the optical chamber and was irradiated by monochromatic light in the direction perpendicular to the gas flow. The transmitted light was recorded by a photomultiplier as a photodetector. The discharge was repeatedly turned on and off, and The discharge was repeatedly turned on and off at one-minute interval so that the plasma gas was generated and led to the optical chamberin every $60 \mathrm{~s}$. According to Yang et al., [Yang X, et al., 2016, J. Phys. D: Appl. Phys. 49,235205-235216] the Natom density was calculated using the transmittance, which was obtained from the ratio of the photodetector signals with and without the plasma gas. 